\title{
PRIMARY DYSMENORRHEA-PATHOPHYSIOLOGY AND MANAGEMENT
}

By

\author{
M. Yusoff Dawood, M.D., M.MED, M.R.C.O.G., F.A.C.O.G. \\ Division of Reproductive Endocrinology \\ Department of Obstetrics and Gynecology \\ University of Illinois College of Medicine \\ Chicago, Illinois
}

DOI: http://dx.doi.org/10.5915/13-4-11971

\section{DEFINITION AND CLASSIFICATION}

The term "dysmenorrhea" as derived from Greek means difficult monthly flow but by usage refers to painful menstruation. The difference between normal menstrual cramps and dysmenorrhea is the need for medication and the inability to function normally in the latter situation. Dysmenorrhea can be classified into primary and secondary dysmenorrhea. Primary dysmenorrhea should be defined as painful menstrual periods in which no macroscopically identifiable pelvic pathology is present, while in secondary dysmenorrhea a macroscopically detectable pelvic pathology is present. Such a classification permits a therapeutic approach and is therefore clinically more helpful in the management of the patient. Classification based on descriptive aspects of the symptom such as congestive dysmenorrhea and spasmodic dysmenorrhea are less useful from a therapeutic standpoint. The causes of secondary dysmenorrhea are given in table 1 .

\section{Table 1. CAUSES OF SECONDARY DYSMENORRHEA}

1. Endometriosis

2. Intrauterine device

3. Pelvic inflammation and infections

4. Adenomyosis

5. Uterine myoma, uterine polyps

6. Congenital malformations of the mullerian system (bicornuate and septate uterus; transverse vaginal septum)

7. Cervical Strictures or Stenosis

8. Ovarian cysts

9. Pelvic congestion syndrome

This review will discuss primary dysmenorrhea only.

\section{INCIDENCE}

The true incidence and prevalence of primary dysmenorrhea has not been clearly established. It varies from community to community and from country to country. Estimates of primary dysmenorrhea run as high as $50 \%$ in postpubescent females and approximately $10 \%$ of those women are incapacitated for I to 3 days each month.

It is the greatest single cause of lost working and school days among young women, with estimates of more than 140 million working hours lost annually'. With the increase of women in the nation's work force, the loss will be greatly compounded but fortunately the availability of new treatments will probably reduce the loss. At an individual level, dysmenorrhea may generate sufficient fear in anticipation of the next menstruation such that mental health during the intermenstrual phase may be severely compromised. Therefore, it is not too difficult to visualize that marital and domestic upheavals may ensue.

\section{CLINICAL FEATURES}

Primary dysmenorrhea occurs almost invariably in ovulatory cycles and usually appears at or within 6-12 months after menarche when ovulatory cycles are established. However, it may set in with the first menstrual flow at menarche. The diagnosis of primary dysmenorrhea made on women with anovulatory cycles is suspect since these are more likely to be secondary dysmenorrhea. Dysmenorrhea starting more than two years after the menarche should arouse suspicion of secondary dysmenorrhea and a high likelihood of endometriosis.

In primary dysmenorrhea, the pains, which are spasmodic in character, are strongest over the lower abdomen, but may radiate to the back and along the thighs. Systemic symptoms include nausea, vomiting,

\section{Address all correspondence to:}

M. Yusoff Dawood, M.D., Department of Obstetrics \& Gynecology, University of Illinois College of Medicine, 840 South Wood Street, Chicago, Illinois 60612 
diarrhea, headache, fatigue, nervousness, dizziness, and in some cases even syncope and collapse. Pelvic pain is accompanied by one or more systemic symptoms in more than 50 percent of dysmenorrheic subjects. ${ }^{1}$ These symptoms include lower backache $(60$ percent), nausea and/or vomiting (89 percent), diarrhea (60 percent), headache (45 percent) and tiredness ( 85 percent). The pains usually start some hours before commencement of visible vaginal bleeding and are most severe on the first day of menstruation, when the woman may be entirely incapacitated from normal activity. The symptoms may last from a few hours to one day but seldom exceed two to three days. In some patients there is a tendency towards spontaneous alleviation of primary dysmenorrhea after the first childbirth but the relief is only temporary for many patients. Advancing age is a better alleviating factor but even this is not invariable.

Pelvic examination is negative in primary dysmenorrhea. It is important that a rectovaginal examination is a sine-qua-non in patients with dysmenorrhea in order to rule out any palpable nodularities or thickenings in the cul-de-sac, uterosacral ligaments and rectovaginal septum which are common sites for endometriosis.

\section{DIAGNOSIS AND INVESTIGATIONS}

The diagnosis of primary dysmenorrhea should be made on its positive clinical features and the important hallmarks are a) the initial onset dates back to the menarche, b) the duration of the dysmenorrhea is usually up to only 48-72 hours with the pain starting usually after the onset of menstrual flow or only a few hours prior to that, c) the character of the pain is cramping or labor-like and d) pelvic examination (including rectovaginal examination) is normal. Differential diagnosis of primary dysmenorrhea includes all the causes of secondary dysmenorrhea which are listed in table 1 , but a major consideration is endometriosis, which can mimic primary dysmenorrhea very closely. In patients who have a family history of endometriosis in a mother or sister and thus have a higher risk of having endometriosis, ${ }^{2}$ laparoscopy should be undertaken early to confirm or rule out endometriosis. Although the age of onset of the dysmenorrhea is often a helpful feature which distinguishes primary from secondary dysmenorrhea, endometriosis has been know to occur soon after the onset of menarche. A history of recurrent pelvic inflammatory disease, irregular menstrual cycles especially associated with anovulation, menorrhagia, the use of an intrauterine device (IUD) and infertility are helpful features in the history which may point towards secondary dysmenorrhea or even the underlying cause of the secondary dysmenorrhea.

Investigations that may be useful in assisting with the diagnosis and cause of the secondary dysmenorrhea include a complete blood count, erythrocyte sedimentation rate, pelvic sonograms, hysterosalpingogram, and genital cultures for pathogens. The final diagnosis can often be made with the aid of diagnostic laparoscopy, hysteroscopy and dilatation and curettage. A hysteroscopy and dilatation and curettage can usually be done together with laparoscopy in these patients when the latter is indicated. Hysteroscopy can provide valuable information on small intra-uterine lesions that a dilatation and curettage may miss.

\section{PATHOPHYSIOLOGY}

\section{a. Psychological Factors ${ }^{3}, 4$}

In the past, many psychological theories have been advanced as the basis for primary dysmenorrhea. However, these studies have established no abnormality in behaviour or contributory psychological factors which are present prior to the development of the disorder. Naturally, with monthly incapacitation and pain, these patients can develop psychological reactions, both to their disorder and their environment. One consideration is the individual response to the mechanism of pain induced by the biochemical disorder. Hence, any manipulation of psychological factors is more likely to influence the response to pain rather than totally remove the biochemical disorder responsible for the pain.

\section{b. Endocrine Factor}

The only proven endocrine factor is the occurrence of primary dysmenorrhea in ovulatory cycles. In anovulatory cycles and in women on the oral contraceptive pill, primary dysmenorrhea does not occur. Thus, in dysmenorrhea associated with anovulatory cycles, careful examination for a pelvic pathology must be performed. A recent investigation ${ }^{5}$ indicated circulating vasopressin levels were elevated in dysmenorrheic women during menstruation when compared to nondysmenorrheic women. The evidence is rather preliminary and since the vasopressin levels were not determined before the onset of menstruation, it is unclear whether the increased vasopressin levels are secondary to the onset of menstruation or precede it.

\section{c. Prostaglandins and Myometrial Activity}

At present it is thought that in primary dysmenorrhea there is increased abnormal uterine activity, which is secondary to increased levels of prostaglandins produced and released by the endometrial tissue at the time of menstruation. ${ }^{\circ}$ The cause of this increased prostaglandin production and release is at present unknown. Because of the hypercontractility of the uterus at menstruation in women with primary dysmenorrhea, blood flow to the 
uterus is compromised and uterine ischaemia occurs Thus, the pain in primary dysmenorrhea is thought to be due to 3 factors: a) increased abnormal uterine activity, b) uterine ischaemia, and c) sensitization of the nerve terminals to prostaglandins and their intermediates by lowering the threshold of these nerve terminals to the action of chemical and physical stimuli. ${ }^{\circ}$

\section{d. Prostaglandins and Dysmenorrhea}

The biosynthesis of prostaglandins and the factors regulating it are summarized in figure 1 and table 2 . At

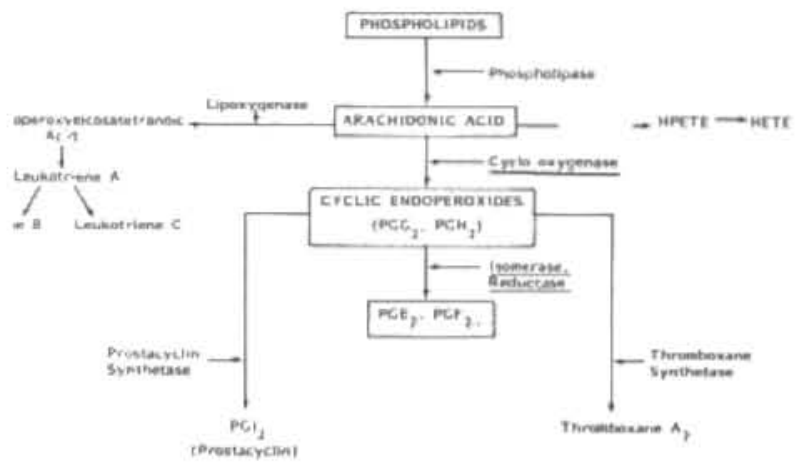

FIG. 1. Simplified pathway for the biosynthesis of prostaglandin synthetase enzymes are underlined.

\section{Table 2. FACTORS REGULATING THE BIOSYNTHESIS OF PROSTAGLANDINS}

\section{Stimulating factors}
a) Availability of precursor fatty acid, arachidonic acid
b) Trauma
c) Estrogen
d) Progesterone
e) Cyclic adenosine monophosphate
f) Luteinizing hormone
g) Epinephrine (adrenaline)

\section{Inhibitory factors}

a) Prostaglandin synthetase inhibitors

b) Corticosteroids

the end of the luteal phase of the menstrual cycle the corpus luteum regresses and progesterone levels fall if pregnancy does not occur. The fall in progesterone levels results in labilization of the lysosomes within the endometrial cells and leads to the release of the lysosomal enzyme, phospholipase $\mathrm{A}_{2}$. Phospholipase $\mathrm{A}_{2}$ then hydrolyzes the phospholipids in the bilipid cell membrane, to generate free arachidonic acid. Arachidonic acid is the main precursor in the biosynthesis of prostaglandin and the more arachidonic acid available, the more prostaglandins produced. Prostaglandins are synthesized from arachidonic acid through the action of several enzymes which are collectively termed prostaglandin synthetase. In the initial step, arachidonic acid is converted to cyclic endoperoxides through the action of the enzyme cyclooxygenase. Subsequently the cyclic endoperoxides are converted into prostaglandins $E_{2}$ and $F_{2} a$ through the action of isomerase and reauctase. I rauma which is occurring at the onset of menstruation together with the increased availabliity of arachidonic acid, are important factors that will stimulate the generation and release of prostaglandins. Prostaglandin synthetase inhibitors act by inhibiting the prostaglandins synthetase enzymes and therefore blocking the production of prostaglandins.

Prostaglandins are $\mathrm{C} 20$ hydrocarbon substances which possess both hydrophobic and hydrophilic properties. These structures are shown in figure 2 . The
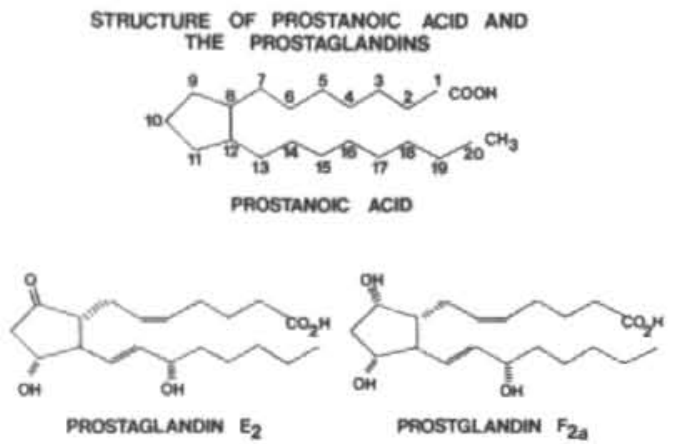

FIG. 2. Structures of prostanoic acid, prostaglandin $\mathrm{E}_{2}$ and prostaglandin $\mathrm{F}_{2} a$.

parent molecule is prostanoic acid which has the cyclopentene ring. The prostaglandins which have been demonstrated to have properties of interest in reproductive medicine are prostaglandin $\mathrm{E}_{2}$ and $\mathrm{F}_{2} a$. Other types of naturally occuring prostaglandins have been found in the last few years, such as the prostacyclins and thromboxanes, but their roles in dysmenorrhea, if any, are presently unclear.

The evidence for the role of prostaglandins in the pathophysiology of primary dysmenorrhea can be summarized as follows.

1. The side effects of prostaglandin $F_{2 a}$ administration both for termination of midtrimester pregnancy and induction of labor at term, include nausea, diarrhea, headache, vomiting and uterine cramps, which are essentially similar to the symptoms of primary dysmenorrhea.

2. Measurements of endometrial and menstrual fluid prostaglandin levels in several studies $7-10$ have indicated significantly higher levels of prostaglandins in women with primary dysmenorrhea, compared with women without dysmenorrhea. (table 3 ). 


\section{Table 3. MENSTRUAL FLUID PROSTA- GLANDIN LEVELS IN NON-DYSMENO- RRHEIC AND DYSMENORRHEIC WOMEN AND IN WOMEN TAKING THE ORAL CONTRACEPTIVE PILL}

MENSTRUAL FLUID PROSTAGLANDINS (ng PGF2 a)(MEAN \pm S.E.)

\section{SUBJECTS}

Non-dysmenorrheic

Primary dysmenorrhea

Dysmenorrheic women using

oral contraciptives

3. Measurement of the metabolite of prosiaglandin $\mathrm{F}_{2}$ a $(15$ keto- 13,14 , dihydro$\mathrm{PGF}_{2 a}$ ) in plasma showed higher levels in women with primary dysmenorrhea compared to normal women."

4. Certain prostaglandin synthetase inhibitors, such as fenamates, indoleacetic acid derivatives, and the arylpropionic acid derivatives, have all been shown to be effective in the treatment of primary dysmenorrhea. During a normal ovulatory menstual cycle both prostaglandin $\mathrm{E}_{2}$ and $\mathrm{F}_{2}$ a levels are low in the endometrium during the proliferative phase, increase slightly during the early luteal phase and then increase four-fold in the late luteal phase and six-fold in the menstrual phase ${ }^{12},{ }^{13}$,

\section{PROSTAGLANDIN SYNTHETASE INHIBITORS}

The nonsteroidal anti-inflammatory agents inhibit the synthesis of prostaglandins and are classified as prostaglandin synthetase inhibitors (PGSI). In addition to inhibiting the prostaglandin synthetase enzymes, some of the inhibitors also have prostaglandin antagonist properties; that is, they block the action of prostaglandins on the target tissue, namely the myometrial cells in the case of primary dysmenorrhea. It has been suggested that the nonsteroidal anti-inflammatory drugs which are prostaglandin synthetase inhibitors can be divided into 2 groups, the type 1 prostaglandin inhibitors and type 2 inhibitors. The type 1 inhibitors inhibit the action of cyclo-oxygenase, which is the enzyme that catalyses the conversion of arachidonic acid to cyclic endoperoxides, while the type 2 inhibitors inhibit the action of the enzymes isomerase and reductase which mediates the conversion of cyclic endoperoxides to $\mathrm{PGE}_{2}$ and $\mathrm{PGF}_{2} a$. Examples of type $\mathrm{I}$ inhibitors are the fenamates, arylpropionic acid derivatives and the indoleacetic acid derivatives. Examples of the type 2 inhibitors are phenylbutazone and p-mercurochlorobenzoate. Since the type 1 prostaglandin inhibitors block the biosynthesis of both cyclic endoperoxides and $\mathrm{PGE}_{2}$ and $\mathrm{PGF}_{2} a$, a greater efficacy can be expected in the treatment of primary dysmenorrhea with type I inhibitors rather than type 2 inhibitors. This is because cyclic endoperoxides have strong uterotonic properties and sensitize the nerve terminals to the chemical and physical stimuli of pain.

There are 5 major categories of nonsteroidal antiinflammatory drugs which are prostaglandin synthetase inhibitors. These five categories are based on the chemical structure of the compounds.

\section{a. Benzoic Acid Derivatives}

An example of a benzoic acid derivative is the well known compound aspirin or acetylsalicylic acid. In two of three clinical trials, aspirin in doses of $650 \mathrm{mg}$ every six hours during the first 2 to 3 days of the menstrual phase was not significantly better than a placebo ${ }^{14}$, is (table 4) However, in one study performed on adolescents, aspirin in doses of $650 \mathrm{mg}$ every 6 hours commencing I day before the onset of menstruation appeared to produce better relief than a placebo ${ }^{16}$. Thus, at present the efficacy of aspirin in the treatment of primary dysmenorrhea remains to be proven. The divergent results reported to date could be related to the dose of aspirin used and the time of administration. Additionally, aspirin has been shown be be ineffective in vitro in inhibiting prostaglandin synthetase but is active in vivo. This has been attributed to the metabolic transformation of aspirin to gentisic acid which is the active component for inhibition of prostaglandin synthetase ${ }^{14}$.

\section{b. Buterophenones}

Examples of compounds with this structure are phenylbutazone and oxyphenbutazone. These are type 2 inhibitors and would therefore be less desirable as a prostaglandin inhibitor of first choice amongst the non-steroidal anti-inflammatory drugs in the treatment of primary dysmenorrhea. Additionally these compounds can potentially produce serious side effects such as blood dyscrasias.

\section{c. Indoleacetic Acid Derivatives}

An example of this group is indomethacin. Indomethacin has been shown to be significantly better than placebo in the treatment of primary dysmenorrhea. Relief has been obtained in 73 to 90 percent of patients ${ }^{17}{ }^{19}$. Indomethacin has been shown to suppress prostaglandin production and release in endometrial tissue as well as suppress uterine activity, thus relieving uterine ischaemia and the symptoms of primary dysmenorrhea.

\section{d. Fenamates}

Examples of these derivatives are the fenamic acids 
which include mefenamic acid, flufenamic acid and tolfenamic acid. Clinical trials with both flufenamic acid and mefenamic acid have shown that they produce significant relief of primary dysmenorrhea in from 77 to 93 percent of patients ${ }^{20}, 22$. Pretreatment before the onset of menstruation is not necessary with the fenamates. It is claimed that the fenamates have prostaglandin antagonist properties. However, in clinical trials, the relief rate obtained is no different from the arylpropionic acid derivative or the idoleacetic acid derivative groups of prostaglandin synthetase inhibitors. One consideration in the use of mefenamic acid is the lack of long term safety data when compared to some of the arylpropionic acid derivatives such as ibuprofen.

\section{e. Arylpropionic Acid Derivatives}

These include compounds such as ibuprofen, naproxen, naproxen sodium, suprofen and ketoprofen. Naproxen and ibuprofen have been extensively tested for their efficacy in primary dysmenorrhea and in many clinical trials have been shown to be highly effective with an efficacy rate ranging from 66 to 100 percent ${ }^{7}-9,14,23,30$. Only one study has been carried out using ketoprofen which shows that it is significantly better than placebo. ${ }^{31}$ With ibuprofen and naproxen there is an accompanying reduction in prostaglandin levels in the menstrual fluid or uterine jet washings with a concomitant reduction in uterine activity and relief of the symptoms of primary dysmenorrhea. With ibuprofen and naproxen pretreatment before the onset of menstruation is not necessary and treatment need only be given for the first 2 to 3 days of the menstrual period.

\section{f. Effect of Treatment on Menstrual Fluid Prostaglandins}

\section{(1) Prostaglandin Synthetase Inhibitors}

The prostaglandin synthetase inhibitors which are nonsteroidal anti-inflammatory drugs also have direct analgesic properties. Thus, at present it is unclear whether the relief of dysmenorrhea by these drugs is purely due to the supression of menstrual fluid prostaglandins or to a direct analgesic effect or a combination of both. In most clinical trials on the efficacy of the nonsteroidal anti-inflammatory drugs in relieving primary dysmenorrhea, assessment has been made only on a clinical and subjective basis for the relief of pain. Three of the prostaglandin synthetase inhibitors, indomethacin, ibuprofen and naproxen, have been shown to reduce endometrial prostaglandin levels during treatment of primary dysmenorrhea with these drugs. With ibuprofen, there is a significant reduction in the amount of prostaglandins released in the menstrual fluid to below normal levels, but without an accompanying reduction in the menstrual fluid volume. Thus the

reduction in menstrual fluid prostaglandins appears to be a direct suppression of the biosynthesis of prostaglandin in the endometrial tissue. In contrast, in women with an intrauterine device there is a reduction in dysmenorrhea as well as $L$ reduction in the menstrual blood loss when a prostaglandin synthetase inhibitor such as flufenamic acid or ibuprofen is given ${ }^{32},{ }^{33}$. The reduction in menstrual fluid prostaglandin is due to the suppression of prostaglandin production and release which normally occurs during the first 48 hours of menstruation ${ }^{8}$.

\section{(2) The Oral Contraceptive Pill}

The combined estrogen-progesterone oral contraceptive pill is effective in relieving primary dysmenorrhea and has been the mainstay of treatment since its introduction. There is a reduction in menstrual fluid prostaglandins to below normal levels in women using the oral contraceptive pill and suffering from primary dysmenorrhea. This reduction is probably the result of two mechanisms: 1) a reduction in the menstrual fluid volume which accompanies the use of birth control pills, since the endometrial tissue growth is suppressed and therefore menstrual loss is reduced and 2) the suppression of ovulation which results in an anovulatory cycle, and an endocrine mileau which is essentially similar to the early proliferative phase of the menstrual cycle when prostaglandins are at the lowest level and luteal phase progesterone levels are absent.

Thus both oral contraceptives and the prostaglandin synthetase inhibitors suppress menstrual fluid prostaglandin levels resulting in relief of primary dysmenorrhea although through somewhat different mechanisms.

\section{g. Drug Dosages}

The doses of nonsteroidal anti-inflammatory drugs used for treatment of primary dysmenorrhea are given in table 4. In most of the studies, it is apparent that

\section{Table 4. DOSAGES OF PROSTAGLANDIN SYNTHETASE INHIBITORS THAT HAVE BEEN USED IN TREATMENT OF PRIMARY DYSMENORRHEA}

\section{DRUG}

1. Indomethacin

2. Flufenamic Acid

3. Mefenamic Acid

4. Tolefenamic Acid

5. Naproxen

6. Naproxen Sodium

7. Ketoprofen

8. Ibuprofen

\section{DOSE}

$25 \mathrm{mg}, 3-6$ time/day

100-200mg, 3 times/day

250-500mg, 3-4 times/day

$133 \mathrm{mg}, 3$ time/day

200-250mg, 4-5 times/day

$275 \mathrm{mg}, 4$ times/day

$500 \mathrm{mg}, 3$ times day

$400 \mathrm{mg}, 4$ times/day 
pretreatment before the onset of menstrual flow is not necessary for effective relief of primary dysmenorrhea as welt as for suppression of endometrial and menstrual fluid prostaglandins. This is of significant importance in clinical practice, as most of the women suffering from primary dysmenorrhea are young and sexually active. Therefore, drugs such as the nonsteroidal anti-inflammatory drugs should preferably be avoided during the late luteal phase of the menstrual cycle as their effects on pregnancy are unknown.

The rapidity with which the drug is absorbed determines the rapidity with which relief of dysmenorrhea is obtained. With rapidly absorbed drugs such as ibuprofen, naproxen or naproxen sodium, there is no significant difference in the menstrual fluid prostaglandin levels whether the drug is taken for 3 days before the onset of menses or if the drug is commenced at the onset of menstrual flow?. The rationale for giving prostaglandin synthetase inhibitors for $\mathbf{4 8}$ hours is based on the observation that prostaglandin production and release is maximal during the first 48 hours of the menstrual flow, as has been shown in studies from our laboratory ${ }^{7}, ?$

If the response to treatment during the first cycle indicates that some degree of uterine cramps persist during the first hour or so of beginning oral medication, then it is recommended that the starting dose be increased by 50 percent or doubled at the next cycle while keeping the maintenance dose essentially the same as before. Thus, with ibuprofen for example if the response to $400 \mathrm{mg} 4$ times daily is unsatisfactory a loading dose of $600 \mathrm{mg}$ at the onset of menstrual flow may be tried before increasing the loading dose to $800 \mathrm{mg}$ at the next cycle, if necessary. The maximum tolerated dose for ibuprofen as recommended by the manufacturers is $2400 \mathrm{mg}$. It is seldom necessary to give women with primary dysmenorrhea more than $2000 \mathrm{mg}$ of ibuprofen per day.

\section{h. Contraindications}

One contraindication to the use of prostaglandin synthetase inhibitors is the presence of gastrointestinal ulcers. Although some of the more recently developed prostaglandin synthetase inhibitors have a lower ulcerogenic index than some of the earlier compounds. at present it is probably prudent to avoid administering these drugs to patients with a definite history of gastric and duodenal ulcers. Prostaglandin synthetase inhibitors should be taken with milk. A relative contraindication is a previous history of a bronchospastic type of reaction after the ingestion of aspirin drugs.

\section{i. Side Effects}

Side effects of prostaglandin inhibitors and antagonists are relatively mild and usually reported to be tolerable.

\section{(1) Indomethacin}

With indomethacin, gastrointestinal side effects have posed a problem in several trials, resulting in high drop-out rates. The side effects of indomethacin include persistent severe headache, severe gastrointestinal symptoms such as nausea, vomiting or dyspepsia and drug rash. The side effects appear to be dose-related. With lower doses of indomethacin such as $25 \mathrm{mg} 2$ to 3 times a day, no side effects were observed. Other serious side effects of indomethacin can include blurred vision, corneal deposits, and retinal disturbances which warrant opthalmological examination; severe headache which if persistent requires discontinuation of the medication; severe gastrointestinal ulcerations with perforation of the esophagus or gut; aplastic anemia, hemolytic anemia and agranulocytosis.

\section{(2) Mefenamic Acid}

Adverse reactions to mefenamic acid include nausea, gastrointestinal discomfort, vomiting, flatulence and diarrhea, severe autoimmune hemolytic anemia, drowsiness, dizziness, nervousness, headache, blurred vision, rash, renal toxicity, and mild hepatic toxicity. In animal studies mefenamic acid decreases fertility and in rabbits it increases the number of fetal resorptions.

\section{(3) Ibuprofen}

Side effects of ibuprofen include gastrointestinal intolerance, skin rashes, dizziness, fluid retention and edema. Ibuprofen is contraindicated in patients who have nasal polyps or angio-edema, bronchospastic reactivity to aspirin, or gastrointestinal ulcers. In animal studies, ibuprofen up to $1600 \mathrm{mg}$ daily did not reveal any evidence of teratogenic effect. However, if is prudent not to administer ibuprofen in suspected pregnancy.

\section{(4) Naproxen}

The side effects of naproxen as used in the treatment of primary dysmenorrhea are considerably less than those associated with indomethacin. Side effects of naproxen may include gastrointestinal disturbances, drowsiness, tiredness, headache and dryness of the mouth but no serious side effects have been reported with this drug in the treatment of primary dysmenorrhea.

Other side effects of prostaglandin synthetase inhibitors include those given in table 5 .

\section{Oral Contraceptives}

The side effects of the combined contraceptive pill are well known and need not be listed here. 
Table 5. SIDE EFFECTS OF PROSTAGLANDIN SYNTHETASE INHIBITORS

\section{Gastrointestinal symptoms}
a) Indigestion
b) Heartburn
c) Nausea
d) Abdominal pain
e) Constipation
f) Vomiting
g) Anorexia
h) Melena

\section{Central nervous system symptoms}
a) Headache
b) Dizziness, vertigo
c) Visual disturbances
d) Hearing disturbances
e) Irritability
f) Depression
g) Drowsiness
h) Sleepiness

\section{Other symptoms}

a) Allergic reactions, (skin rash, edema)

b) Bronchospasm

c) Hamatological

d) Effects on the eye

e) Fluid retention

f) Effects on the liver and kidneys

\section{CLINICAL MANAGEMENT OF PRIMARY DYSMENORRHEA}

It is essential that the physician spends time talking to the patient, explaining about the disorder and what can be expected from the modern approach to treatment of primary dysmenorrhea, regardless of the medication chosen. If such a dialogue is carried out in the correct manner, it will have psychotherapeutic benefit to the patient with respect to her response to pain and thus improve the outcome of the pharmacotherapy. An outline of the management of primary dysmenorrhea is given in table 6 . The choice of medication will depend on whether the woman requires an oral contraceptive for birth control, and if there is any contraindication to the use of a combined oral contraceptive or the use of a prostaglandin synthetase inhibitor. Thus, if the patient wants birth control with the combined oral contraceptive, this would be the drug of choice in the treatment of primary dysmenorrhea in this category of women. The effect of the oral contraceptive pill is to inhibit ovulation, reduce endometrial growth and therefore menstrual fluid volume, with an accompanying reduction in menstrual fluid prostaglandins (see above). Relief of primary dysmenorrhea can be obtained in at least 90 percent or more of women with primary dysmenorrhea and a trial of the oral contraceptive for a period of 3 months is worthwhile. If the patient responds to the oral contraceptive, she can then be maintained on this regimen.

On the other hand if there is no response, to the birth control pill, then an appropriate prostaglandin inhibitor can be added at this time. The choice of the prostaglandin synthetase inhibitor is based on the clinical evidence of its efficacy as well as some of the theoretical considerations listed in table 7 . It may be

\section{Table 7. CRITERIA FOR CHOOSING AN IDEAL PROSTAGLANDIN SYNTHETASE INHIBITOR IN THE TREATMENT OF DYSMENORRHEA.}

(From Dawood MY. ${ }^{34}$ ).

1. Should be effective in inhibiting endometrial prostaglandin synthesis.

2. Should be a type 1 prostaglandin synthetase inhibitor; i.e. an inhibitor which blocks cyclooxygenase activity.

3. Should be rapidly absorbed to achieve therapeutic blood levels quickly.

4. Should preferably possess prostaglandin antagonist properties, i.e., block myometrial prostaglandin receptors.

5. Low ulcerogenicity

6. Side effects, if any, must be minimal, tolerable and inconsequential.

7. Low term safety.

necessary to increase the dose (see above), if there is incomplete relief during the first cycle of treatment. If there is still no improvement, it may be necessary to try a different prostaglandin synthetase inhibitor.

If the patient does not wish to use an oral contraceptive as a method of birth control, the drug of choice for the treatment of primary dysmenorrhea is a prostaglandin synthetase inhibitor. This form of therapy has advantages over birth control pills, as treatment is restricted to 2 to 3 days of the menstrual cycle, whereas the oral contraceptive has to be given for a minimum of 3 weeks out of 4 . In addition there is no significant suppression of the pituitary-ovarian axis and there are none of the metabolic effects which are seen with the oral contraceptive. The choice of prostaglandin synthetase inhibitor has been referred to above. A trial with prostaglandin inhibitors of up to 6 months duration with the necessary changes in dosage or the type of inhibitor, should the one chosen not work effectively, will be sufficient to show whether or not relief will be obtained. 
If the patient does not respond to a prostaglandin synthetase inhibitor, then it is appropriate to reconsider whether pelvic pathology which is not palpably detectable and which constitutes secondary dysmenorrhea may have been missed. At this point, a laparoscopy should probably be performed to rule out or confirm a pelvic disease. In the event that a pelvic disease is discovered, then the appropriate treatment will be directed toward the underlying pathology and the dysmenorrhea should at the same time be alleviated. If a pelvic pathology is not found, it is at present unclear whether any pharmacological agent could be of help to these patients. Patients who do not have any demonstrable pelvic pathology on laparoscopy, and who have not responded to either an oral contraceptive, a prostaglandin synthetase inhibitor or a routine analgesic, should be given a trial of a B-sympathomimetic agent such as isoxsuprine hydrochloride, terbutaline sulphate or ritodrine hydrochloride. If no satisfactory response is obtained, then referral for psychiatric treatment may be appropriate. This group of patients should be very small if the correct diagnosis and earlier steps in the management of the patient have been undertaken.

\section{SUMMARY OF THE MANAGEMENT OF PRIMARY DYSMENORRHEA}

1. Confirm the diagnosis of primary dysmenorrhea.

2. Discuss the contraceptive desires of the patient.

3. If the patient wishes to use the birth control pill, prescribe a combined oral contraceptive and observe for 3 months.

4. If the patient obtains relief of the dysmenorrhea, maintain therapy; if not, continue the oral contraceptive for contraception but add a prostaglandin synthetase inhibitor (e.g. ibuprofen, naproxen, flufenamic acid) for the first 3 days of the menstrual flow; adjust dose and if necessary change to another agent if no relief is obtained after approximately 3 months.

5. If the patient obtains relief of symptoms continue treatment as in 4. If no relief is obtained after 6-9 months of prostaglandin synthetase inhibitor therapy, a laparoscopy is indicated to rule out pelvic pathology such as endometriosis.

6. If the patient does not wish to use the oral contraceptive for birth control and has no gastric or duodenal ulcers, prescribe a suitable prostaglandin synthetase inhibitor, adjust the dose and/or change to another prostaglandin synthetase inhibitor as necessary.

7. If after 6-9 months of prostaglandin synthetase inhibitor therapy, there is inadequate relief of dysmenorrhea, a laparoscopy is indicated to rule out pelvic pathology such as endometriosis.
8. If the patient has a gastric ulcer, recommend the use of an oral contraceptive; if this is refused, or the patient has a contraindication to the oral contraceptive, management becomes difficult. Referral to a gynecologist with an interest in dysmenorrhea is appropriate. Other experimental forms of therapy are under study.

\section{REFERENCES}

1. Ylikorkala, O. and Dawood, M.Y. New Concepts in Dysmenorrhea. Am. J. Obstet. Gynecol. 130:833, 1978.

2. Simpson, J.L., Elias, S., Malinak, L.R. and Buttram, V.C. Heritable Aspects of Endometriosis. 1. Genetic Studies. Am. J. Obstet. Gynecol. 137:327, 1980.

3. Astrachan, J.M. The Psychiatric Treatment of Primary Dysmenorrhea. In DYSMENORRHEA edited by M,Y. Dawood, Williams \& Wilkins, Baltimore in press 1981.

4. Cox, D.J. and Santirelli, L.L. Psychological and Behavioural Factors in Dysmenorrhea. In DYSMENORRHEA edited by M.Y. Dawood, Williams \& Wilkins, Baltimore in press 1981.

5. Akerlund, M., Stromberg, P. and Forsling, M.D. Primary Dysmenorrhea and Vasopressin. Br. J. Obstet. Gynecol. 86:484, 1979.

6. Dawood, M.Y. Hormones, Prostaglandins and Dysmenorrhea. In DYSMENORRHEA edited by M.Y. Dawood, Williams \& Wilkins, Baltimore in press 1981.

7. Chan, W.Y., Dawood, M.Y. and fuchs, F. Relief of dysmenorrhea with the prostaglandin synthetase inhibitor ibuprofen: effect on prostaglandin levels in menstrual fluid. Am. J. Obstet. Gynecol. 135:102, 1979.

8. Chan, W.Y. and Dawood, M.Y. Prostaglandin levels in menstrual fluid of non-dysmenorrheic and of dysmenorrheic subjects with and without oral contraceptive or ibuprofen therapy. Adv. Prostaglandin Thromboxanes Res. 8: 1443, 1980.

9. Chan, W.Y., Dawood, M.Y. and Fuchs, F. Prostaglandin in Primary Dysmenorrhea. Comparison of prophylactic and non-prophylactic treatment with ibuprofen and use of oral contraceptives. Am. J. Med. 70:535, 1981.

10. William, E.A. Collins, W.P. and Clayton, S.G. Studies in the Involvement of Prostaglandin in Uterine Symptomatology and Pathology. Br. J. Obstet. Gynaecol. 83:337, 1976.

11. Lundstrom, V, and Green, K. Endogenous levels of prostaglandin F2 and its Main Metabolites in Plasma and Endometrium of Normal and Dysmenorrheic Women. Am. J. Obstet. Gynecol. 130:640, 1978. 
12. Downie, J., Poyser, N.L. and Wunderlich, M. Levels of Prostaglandins in Human Endometrium During the Normal Menstrual Cycle. J. Physiol. 236:465, 1974.

13. Singh, E.J., Baccarini, I.M. and Zuspan, F.P. Levels of Prostaglandins F2 and E2 in Human Endometrium During the Menstrual Cycle. Am. J. Obstet. Gynecol. 121:1003, 1975.

14. Corson, S.L. and Bolognese, R.J. Ibuprofen Therapy for Dysmenorrhea. J. Reprod. Med. 20:246, 1978.

15. Janbu, T., Lokken, P. and Nesheim, B.I. Effect of Acetylsalicylic Acid, Paracetamol and Placebo in Pain and Blood Loss in Dysmenorrheic Women. Acta. Obstet. Gynaecol. Scand. (Suppl) 87:81, 1979.

16. Klein, J.R. and Litt, I.F. Trial of Prostglandin Synthetase Inhibitor. Acetylsalicylate on a Population of Severely Dysmenorrheic Adolescents. A double-blind, cross-over study. Presented at he Society of Pediatric Research, San Antonio, Texas (May 1980).

17. Hamann, G.O. and Laursen, B. Primaer Dysmenore Behandlet Med. Indomethacin. Ugesk. Laeger. 139:1899, 1977.

18. Kajanoja, P. and Vesanto, T. Naproxen and Indomethacin in the Treatment of Primary Dysmenorrhea. Acta Obstet. Gynaecol. Scand. (Suppl.) 87:87, 1979.

19. Kauppila, A. and Ylikorkala, O. Indomethacin and Tolefenamic Acid in Primary Dysmenorrhea. Eur. J. Obstet. Gynecol. Reprod. Biol. 7:59, 1977.

20. Anderson, A.B.M., Haynes, P.J. Fraser, I.S. and Turnbull, A.C. Trial of Prostaglandin-synthetase Inhibitors in Primary Dysmenorrhea. Lancet 1:345, 1978.

21. Kapadia, L. and Elder, M.G. Flufenamic Acid in Treatment of Primary Spasmodic Dysmenorrhea. A double-blind cross-over study. Lancet I:348, 1978.

22. Budoff, P.W. Use of Mefanamic Acid in the Treatment of Primary Dysmenorrhea. J.A.M.A. 241:2713, 1979.

23. Dandenell, L.O., Lalos, O., Pisciak, J., Sandstrom, B., Barany, S. and Nilsson, B. Clinical Experience of Naproxen in the Treatment of
Primary Dysmenorrhea. Acts. Obstet. Gynaecol. Scand. (Suppl.) 87:95, 1979.

24. Hamann, G.O. Severe Primary Dysmenorrhea Treated with Naproxen. A prospective, doubleblind, cross-over investigation. Prostaglandins 19:651, 1980.

25. Jacobson, J., Cavalli-Bjorkman, K., Lundstrom, V., Nilsson, B, and Norbeck, M. Prostaglandin Synthetase Inhibitors and Dysmenorrhea. A survey and personal clinical experience. Acta Obstet. Gynaecol. Scand. (Suppl.) 87:73, 1979.

26. Henzl, M.R., Buttram, V. Segre, E.J., Bessler, S. The Treatment of Dysmenorrhea with Naproxen Sodium. A report of two independent doubleblind trials. Am. J. Obstet. Gynecol. 127:818, 1977,

27. Henzl, M.R. and Izu, A. Naproxen and Naproxen Sodium in Dysmenorrhea: Development from in vitro Inhibition of Prostaglandin Synthesis to Suppresion of Uterine Contractions in Women and Demonstration of Clinical Efficacy. Acta. Obstet. Gynaecol. Scand. (Suppl) 87:105, 1979.

28. Lundstrom, V. Treatment of Primary dysmenorrhea with Prostaglandin Synthetase Inhibitors a Promising Therapeutic Alternative. Acta. Obstet. Gynaecol. Scand. 57:421, 1978.

29. Larkin, R.J., Van Orden, D.E., Paulson, A.M. and Scott, J.R. Dysmenorrhea: Treatment with an Antiprostaglandin. Obstet. Gynecol. 54:456, 1979.

30. Layes Molla, A. and Donald, J.F. A Comparative Study of Ibuprofen and Paracetamol in Primary Dysmenorrhea. Internat. Med. Res. 2:395, 1974.

31. Kaupilla, A., Poulakka, J. and Ylikorkala, C. The Relief of Primary Dysmenorrhea by Ketoprofen and Indomethacin. Prostaglandin 18:647, 1979.

32. Anderson, A.B.M., Gillebaud, J., Haynes, P.J. and Turnbull, A.C. Reduction of Menstrual Blood-loss by Prostaglandin Synthetase Inhibitors. Lancet 1:774, 1976.

33. Roy, S. Personal Communication. 1980.

34. Dawood, M.Y. Overall Approach to the Management of Primary Dysmenorrhea. In DYSMENORRHEA edited by M.Y. Dawood, Williams \& Wilkins, Baltimore in press, 1981. 